\title{
EL ESTATUS DE LA NOCIÓN DE CERTEZA EN WITTGENSTEIN
}

\section{THE STATUS OF WITTGENSTEIN'S NOTION OF CERTAINTY}

\author{
Patricia King Dávalos \\ Universidad Autónoma del Estado de Morelos
}

Recibido: 6 de diciembre, 2013 • Aceptado: 12 de mayo, 2014

Resumen: En este artículo hago ver que Ludwig Wittgenstein considera al conocimiento empírico no solo como una cuestión de justificación lógica de proposiciones, ya que la fundamentación de un argumento, o serie argumental, depende esencialmente de un sistema de certezas enraizadas en las prácticas adquiridas en el contexto de una comunidad histórico-social de hablantes.

Palabras clave: formas de vida, certeza, conocimiento.

Abstract: In this article I show that Ludwig Wittgenstein considers empirical knowledge not just as a question of logical justification of propositions, since the foundation of a specific argument, or series of arguments, depends on certainty's system rooted in the practices acquired by the social-historical context of a community of speakers.

Keywords: forms of life, certainty, knowledge. 


\section{Introducción}

$\mathrm{P}$ or muchos siglos, al menos desde la Grecia Clásica hasta el S. XX, muchos filósofos estaban convencidos de que saber algo era lo mismo que tener una creencia, verdadera justificada. ${ }^{1}$ También había un gran acuerdo en que "estar justificado" quería decir dar y tener buenas razones para convencer a cualquier interlocutor de que lo que uno creía que era verdadero (Villoro, 1987, p. 14-17). En este contexto, George E. Moore y Ludwig Wittgenstein sostuvieron una discusión cuando Moore, levantando su mano frente a su vista, dijo: sé que ésta es mi mano. Wittgenstein le contestó: no, tú no sabes que esa es tu mano. Este gran filósofo reflexionó sobre dicho tema al menos durante varios años, y si lo abandonó fue porque falleció en 1951, justamente dos días después de haber escrito las últimas líneas de su obra póstuma Sobre la certeza. Considero que la relevancia de esta obra para la epistemología ha sido poco estudiada y difundida, ${ }^{2}$ a pesar de constituir un cambio paradigmático para esta. Los aportes de Wittgenstein, se han considerado seriamente más bien en el ámbito de otros campos filosóficos, principalmente en el marco de la Filosofía del Lenguaje. Sin embargo, considero que el artículo "Wittgenstein: epistemología y lenguaje" escrito por Andrés Gallardo, es uno de los pocos trabajos en castellano que señalan detalladamente la gran importancia que el pensamiento de Wittgenstein tiene específicamente para la epistemología contemporánea y estoy de acuerdo con él cuando afirma: "Wittgenstein sostuvo (en el segundo periodo) que la significatividad del lenguaje humano [...] obedece al modo en que se utilizan las palabras en diversos contextos; estos contextos dependen, a su vez, de las "formas de vida" de una comunidad" y, refiriéndose a los distintos problemas fundamentales que el gran filósofo austriaco alumbró, agrega: "Uno de estos problemas fundamentales atañe al estatus y la naturaleza del conocimiento"

1 Aun cuando se expresaba de diferentes maneras, ésta era una caracterización ampliamente compartida hasta que se puso en duda a mediados del siglo XX, en particular, con los famosos contraejemplos de Edmund Gettier.

2 Para un panorama general de las polémicas en torno a las interpretaciones en el campo de la epistemología de la obra Sobre la certeza de Wittgenstein, recomiendo la lectura del libro editado por Daniele Moyal-Sharrok (2004) y el compilado por Daniele Moyal-Sharrok \& William Brenner (2007) en inglés. Para lecturas en castellano, recomiendo: Pinto, S. 2004; Ariso, J. M. 2008, 2012; Fernandois, E. 2013 y Santibañez, C. 2011, 2012. 
(Gallardo, 2011, p. 88). Sin embargo, Gallardo menciona la noción de "certeza" solo una vez en su artículo. Desde mi punto de vista, resaltar esta noción es de gran relevancia para la epistemología, porque, como trataré de hacer ver, involucra un tipo de normatividad implícita en el hacer cotidiano de una comunidad en un contexto histórico social determinado. Uno de los propósitos de este artículo es servir como complemento de las afirmaciones de Gallardo que he mencionado. ${ }^{3}$

Otro de mis objetivos, es esclarecer la noción de "certeza" tal y como considero que la concibe Wittgenstein. Esto es así, porque estoy convencida de que el fenómeno que llamamos "certeza" lo experimentamos todos, el problema es que, al menos desde la modernidad, se le ha identificado en términos de infalibilidad y otros similares. Wittgenstein no lo concibe así, y lo aborda de una manera tan diferente que aporta elementos relevantes para apoyar y desarrollar esas dos ideas de Gallardo antes dichas. También quiero mostrar, que la concepción wittgensteiniana de "certeza" permitiría comprender dicho fenómeno dándole una vuelta de $180^{\circ}$ a la manera cartesiana de explicarlo y distinguirlo. Por esta razón, en este trabajo intentaré describir de manera conspicua cuáles fueron las razones que Wittgenstein ofreció para afirmar, en contraposición a Moore, "Si sabes que aquí hay una mano, te concederemos todo lo demás” (Wittgenstein, 1991, §1), ${ }^{4}$ refiriéndose al modo en el que Moore defendía la pretensión de saber, con toda seguridad, que esa era su mano o, para decirlo en términos filosóficos, para defender su concepción acerca del conocimiento de sentido común que, según Moore, es un conocimiento que todos tenemos acerca del mundo en el que vivimos. ${ }^{5}$

Se trata de un trabajo exegético, lo más apegado que pude a Sobre la Certeza, en el que me propongo hacer ver -a través de la extracción de un

3 Mi pretensión es solo apoyar esas dos afirmaciones, más no polemizar con el autor. Una reflexión crítica acerca de la posición con la que respalda dichas afirmaciones, correspondería a otro artículo distinto al que aquí presento. Sin embargo, considero de gran importancia, como lo hace Gallardo, integrar el pensamiento epistemológico de Wittgenstein al ámbito de la "Disputatio" entre las teorías rivales del conocimiento que están en curso, algo que harto poco se ha hecho.

4 Cabe aclarar que Sobre la certeza, es una obra organizada a través de una serie de aforismos numerados del 1 al 676, apareciendo varios de ellos en una sola página; por esta razón las confrontaciones así como las citas de dicha obra las llevo a cabo en términos de los aforismos correspondientes a la versión en alemán y en español (marcados con '§’) de la parte en español y no al número de la página en donde aparecen.

5 Es en su ensayo publicado en 1939, Moore afirma, mostrando su mano, que él sabe que esa es su mano. 
ramal de la trenza que constituye las excelentes y numerosas series con las que Wittgenstein nos ofrece un complejo movimiento argumental en Sobre la certeza- que Wittgenstein sostiene que sí hay certezas, que todos los hablantes las tenemos corporizadas en nuestras prácticas contextuales, ${ }^{6}$ que aquellas no son conocimiento y que, sin embargo, constituyen el fundamento de todo el conocimiento acerca del mundo en una época históricamente determinada.

Comenzaré, con el propósito de mejor comprender la serie argumental que nos ocupará, exponiendo otras nociones de Wittgenstein las cuales se relacionan íntimamente con la de "certeza". Así, al abordar la idea central de su razonamiento: un sistema de certezas corporizadas en prácticas contextuales y su significación para el conocimiento, no tendremos que detenernos en caracterizaciones que puedan romper el hilo de su argumento central.

Wittgenstein, en varios lugares de la obra que nos ocupa, nombra "juegos del lenguaje” a las prácticas lingüísticas que compartimos con nuestros semejantes desde los primeros meses de nuestro nacimiento en el marco de una comunidad de hablantes. Siguiendo esta idea me planteé la siguiente pregunta: ¿Qué sentido tiene tal o cual juego lingüístico en Sobre la certeza? La he contestado tratando de jugar con los aforismos expresados en esta obra, respondiendo así a las preguntas y desafíos que Wittgenstein lanza continuamente al lector. Lo hice saltando de un aforismo a otro sin seguir el orden numérico de los mismos, sino más bien tratando de ver si en alguno de ellos, el mismo Wittgenstein los respondía u ofrecía más pistas para mi reflexión e interpretación coherente sobre alguna de sus series argumentales. Así he querido descubrir el significado de distintas nociones usadas por él. La inquietud que me llevó a abordarlo de esta manera fue la sospecha (¿debiera decir la duda?) respecto a una posible estructura formal de alguno de sus movimientos argumentales: una serie de juegos lingüísticos que hay que combinar, separar o unir de distintas maneras, a juicio del lector, para poder responder a dichos desafíos y preguntas del autor. En todo caso, como él mismo lo dice, aprendemos a jugar jugando.

6 Wittgenstein no lo formula así. Más bien el término "corporizado" es usado en el marco de la ciencias cognitivas para expresar la idea de que el conocimiento o la cognición, no dependen solo del cerebro, sino del sujeto cognitivo integral, es decir del sujeto cognitivo real, activo (constituido por un cuerpo que, por supuesto, incluye un cerebro). Para una justificación del uso de dicho término en el contexto de Sobre la certeza, véase la nota 17 de este trabajo. 
Estoy de acuerdo con Gallardo en que en esta obra, Wittgenstein despejó un nuevo horizonte que permite continuar la vieja polémica en torno a la epistemología o teoría del conocimiento bajo nuevos términos, ya que nos ofrece la oportunidad de replantear las cuestiones más relevantes de la epistemología contemporánea desde una perspectiva muy diferente a la dominante en la tradición filosófica.

\section{Las formas de vida y las imágenes del mundo}

Para Wittgenstein en una imagen del mundo encontramos el orden de palabras y oraciones que constituyen el lenguaje compartido por una comunidad de hablantes. La imagen del mundo de una comunidad de hablantes, es producto de las prácticas adquiridas o aprendidas por el solo hecho de nacer y crecer en ella, es decir, de la forma de vida correspondiente dicha comunidad. Las formas de vida de las comunidades en una cultura o de una cultura a otra, cambian históricamente y, por ende, las imágenes del mundo van cambiando en correspondencia.

La imagen del mundo que me transmiten los adultos a lo largo de mi infancia funciona como las reglas de un juego. Comienzo a aprender este juego desde mi más tierna edad, pero no memorizando sus reglas sino más bien jugándolo prácticamente con mis semejantes. ${ }^{7}$ Por ejemplo, es típica la siguiente sucesión de juegos conforme vamos creciendo: “¡Mira qué manos tan sucias tienes!, vamos a lavarlas". "Lávate las manos Juan que ya vamos a comer”. “¡No pongas ahí la mano!”. “Cómo te cortaste esa mano?”. "Da la mano, pequeño", entre otras. Muy pronto el pequeño, siguiendo imperceptiblemente las reglas del juego, al lastimarse comienza a brincar mientras balbucea lloroso mostrando su mano: "Mano, jay, ay!”. Así aprendemos el significado de la palabra "mano": usando la palabra a través de nuestras interacciones prácticas y cotidianas con nuestros padres y otras personas. Podemos imaginar una gran multiplicidad de situaciones en las que van apareciendo, a través de diferentes acciones, prácticas y juegos lingüísticos, las distintas palabras que conforman nuestro lenguaje natural y al que accedemos en su forma más básica a escasos dos o tres años de edad.

7 Véase Wittgenstein, 1991, § 93-95. 
Construyendo distintos juegos del lenguaje, es decir, usando las palabras, acomodándolas de manera más o menos apropiada, combinándolas y expresándolas, el pequeño va poco a poco "capturando implícitamente”, adquiriendo, las reglas del juego lingüístico y comprendiendo así el significado de las palabras: -"imesa tonta!"; -’No, la mesa no es tonta, solo la gente puede serlo, si no te fijas por dónde caminas el tonto eres tú" (Wittgenstein, 1991, § 29). Los juegos del lenguaje se van hilando entre sí para dar lugar a complejos familiares de juegos cada vez más intrincados. El niño va aprendiendo así las prácticas enraizadas en las formas de vida que distinguen a su comunidad. También aprende a creer lo que le cuentan los adultos, ${ }^{8}$ lo que le enseñan sus profesores, lo que lee en sus libros de texto. ${ }^{9}$ Más tarde, el joven podrá salir de su comunidad más familiar y se iniciará en múltiples y nuevos juegos lingüísticos específicos, ${ }^{10}$ aquellos de los distintos grupos más o menos numerosos que conforman su país, su continente o los de otros continentes. Los siguientes aforismos constituyen una de las síntesis más claras de lo que Wittgenstein (1991) entiende por imagen del mundo:

Aprendí una gran cantidad de cosas y las acepté en base a la autoridad humana...(§161)

Pero no tengo mi imagen del mundo porque me haya convencido a mí mismo de que es correcta. Por el contrario, se trata del trasfondo que me viene dado... (§ 94)

Así pues, la noción de imagen del mundo en Wittgenstein es una cosa complicadísima: surge de la tradición, de los usos y costumbres de una determinada comunidad humana, sus hábitos, las prácticas y creencias de sus miembros, sus acciones, actitudes y comportamientos, la manera como se relacionan unos con otros, la forma como juzgan los hechos, los conocimientos que han logrado adquirir, en una palabra de la interacción de entre los miembros de una comunidad en determinado contexto. ${ }^{11}$ Es, pues, el trasfondo a través del cual aprehendo al mundo interaccionando, en diversos planos con mis semejantes. Las reglas que rigen el juego del lenguaje se van

8 Véase Wittgenstein, 1991, §160, §286.

9 Véase Wittgenstein, 1991, §162, §286, §288.

10 Véase Wittgenstein, $1991 \$ 347$.

11 Véase Wittgenstein, 1991,§ 63, 93, 94, 95, 130. 
adquiriendo implícitamente, de manera casi imperceptible y contienen los criterios valorativos de sentido y sin sentido del uso de las palabras ${ }^{12}$.

Por ejemplo, la oración “¡Mira, ya llegaron los Santos Reyes!” tiene sentido porque podemos imaginar un contexto ${ }^{13}$ en el que se cumple con la norma, digamos aquel en el que, en nuestra sociedad, un padre hace tal exclamación dirigiéndose a su hijito al mostrarle su árbol de navidad lleno de regalos ese día del año. Pero esta misma exclamación -¡Miren, llegaron los Santos Reyes! - hecha por un señor que presencia cómo un coche atropella a una persona dejándola malherida, suscitará por aquellos que también presenciaron el accidente y escucharon tal exclamación, la idea de que el significado de dicha exclamación en esos momentos no tiene sentido, expresando esta idea, o con su hacer: alejándose de tal señor, o con creencias o exclamaciones del tipo de "ese señor está loco", "es un indolente", "está drogado", entre otras. Esto significa que los juegos lingüísticos están corporizados, ${ }^{14}$ dependen del contexto y del uso adecuado de las palabras y de las acciones que a aquellas complementan. Según Wittgenstein, adquirimos la habilidad de distinguir si un juego lingüístico está fuera de contexto o si las palabras están mal expresadas, mediante nuestra práctica de usarlas en determinadas situaciones a lo largo de la vida. De hecho, en la vida cotidiana de todas las personas, no hay ningún criterio evaluativo sobre la normatividad del sentido o los juicios correctos o incorrectos que hacen. "La práctica de usar una regla muestra también qué es un error en su utilización”. ${ }^{15}$

12 Véase Wittgenstein, 1991, §10.

13 Véase Wittgenstein, 1991, \$237.

14 Me atrevo a usar la metáfora "los juegos lingüísticos están corporizados" en un sentido similar al uso de la noción "cognición corporizada" en el marco de la Cognición Situada en Ciencias cognitivas, es decir en el sentido de que no es posible comprender y explicar la cognición humana limitándola a una parte interna del cuerpo del sujeto cognoscente, en este caso al cerebro, sino que necesario estudiarla como una propiedad (no de un cerebro aislado) de una persona integral en interacción con otras personas en el medio de su ambiente físico y social. Análogamente, la metáfora "los juegos del lenguaje" de Wittgenstein, corresponde a la diversidad de usos que una persona puede hacer de sus emisiones lingüísticas, como tal persona, en interacción práctica con otras personas en su ambiente físico y social; en otras palabras en el medio de sus formas de vida de las cuales surgen sus imágenes del mundo. No es posible analizar el lenguaje como un lenguaje privado, un lenguaje que fuese únicamente interno a una persona; el lenguaje es un asunto público, nos dirá Wittgenstein en las Investigaciones filosóficas (2003).

15 Wittgenstein, 1991, §29. 
Desde el punto de vista del lenguaje común o creencias de sentido común, podemos cometer errores que no pueden ser calificados de sinsentido, sino de juicios falsos. En este caso se trataría, por ejemplo, de una confusión de los hechos por mi parte o de una confusión de las palabras, pero en ambos casos dentro de contextos apropiados al juego lingüístico y tales que no puede decirse, estrictamente hablando, que se ha violado la regla. Por ejemplo, en los casos en los que al dar información a un tercero sobre las acciones de otro, resultase de una confusión: -"Laura, te vi muy temprano en la cafetería"; -"No, a quien viste fue a mi hermana gemela que recién llegó de París". Bajo estas condiciones, la oración "Laura, te vi..." es a todas luces falsa, pero no podemos calificarla de sinsentido. Otro ejemplo es cuando digo una palabra habiendo querido decir otra (situación harto común).

Un ejemplo más, referido a lo que consideramos verdadero o falso en la vida cotidiana, lo encontramos en la siguiente situación ejemplar: muchos pequeños creen en la real existencia de los Santos Reyes, pero tarde o temprano ponen en duda dicha creencia y ante nueva evidencia adquirida en contra de ésta, deciden desecharla. ${ }^{16}$ En algunos casos es notoria su búsqueda por confirmar su sospecha, pero una vez convencidos de la falsedad de su creencia, de inmediato deciden deshacerse de ésta, sin embargo en otros casos su vieja creencia simplemente se extinguirá poco a poco porque chocará con nuevas experiencias, creencias, actitudes y acciones (suyas y de otros); en una palabra: comienza a chocar con parte del sistema de aquello que cree. ${ }^{17}$ El niño pronto se convencerá prácticamente de que tal creencia es falsa. ${ }^{18}$ A partir de sus juegos del lenguaje, decide que alguna nueva creencia es verdadera porque ensambla mejor con el resto de sus creencias ${ }^{19} \mathrm{y}$, en general, con la imagen del mundo que va adquiriendo progresivamente: ${ }^{20}$

Aprendí una gran cantidad de cosas y las acepté en base a la autoridad humana. Después he descubierto que se veían confirmadas o refutadas por mi propia experiencia (Wittgenstein, 1991, §161).

16 Véase Wittgenstein, 1991, §160, 200.

17 Véase Wittgenstein, 1991, §105, 106, 107, 108.

18 Véase Wittgenstein, 1991, \$200.

19 Véase Wittgenstein, 1991, §83, 225

20 Véase Wittgenstein, 1991, §144, 162. 
Pero no tengo mi imagen del mundo porque me haya convencido a mi mismo de que sea correcta; ni tampoco porque esté convencido de su corrección. Por el contrario, se trata del trasfondo que me viene dado y sobre el que distingo entre lo verdadero y lo falso (Wittgenstein, 1991, §94).

La proposición es verdadera o falsa" sólo quiere decir que ha de ser posible decidir a favor o en contra de ella. Pero con ello no se proporciona el tipo de fundamento que corresponde a tal decisión (Wittgenstein, 1991, §200).

\section{La tesis sobre las certezas}

Concibiendo a la certeza como un estado total de convicción y ausencia de toda duda, ${ }^{21}$ Wittgenstein sostiene la siguiente la siguiente tesis: las certezas están en el fundamento de todo conocimiento y son la consecuencia obligada de nuestras prácticas contextuales, pero no son conocimiento ellas mismas ${ }^{22}$.

En los juegos del lenguaje, cuando consideramos que no podemos equivocarnos, parece que podemos expresar nuestra certeza mediante proposiciones de la forma "sé que tal y tal". Un ejemplo de tales proposiciones es la mencionada afirmación de Moore: "sé que aquí hay una mano". Ahora trataré de hacer ver por qué Wittgenstein no estuvo de acuerdo con que dicha afirmación fuera precedida de la palabra "sé que".

Para Wittgenstein "Sé que esta es mi mano" o "Sé que tal y tal", corresponde a una presunción de conocimiento. Si esto es así, entonces "Sé que tal y tal" compromete a quien lo dice, digamos a Juan, a ofrecer buenas razones que le permitan apoyar y sostener con razones su afirmación ante cualquier interlocutor, ya que habrá personas que estén de acuerdo y personas que no estén de acuerdo con lo que Juan afirma saber. Sin embargo, Wittgenstein dice "Las verdades que Moore afirma saber son tales que, dicho sea de paso, si él las sabe, todos las sabemos" (Wittgenstein, 1991, §100).

Esto es así porque, para Wittgenstein, afirmar que "esta es mi mano" mostrándola, es una certeza, y no puedo negar ni una sola de mis certezas porque las negaría todas. No podría creer lo contrario a una de mis certezas porque:

21 En este sentido, véase, Wittgenstein, 1991, principalmente $§ 39,102,103,108,114,115,116$, 121, 123, 174, 273, 280, 298.

22 Véase, Wittgenstein, 1991, §109, 110, 111, 112. 
... tal cosa no se ajustaría de ningún modo al resto de mis convicciones, aunque no pudiera describir el sistema de estas convicciones. Mis convicciones constituyen un sistema, un edificio (Wittgenstein, 1991, §102).

\section{Series argumentales}

Wittgenstein sostiene que de la declaración: 'Sé que tal y tal', "no se sigue que lo sepa" (Wittgenstein, 1991, §13), ya que cuando digo "Sé que...”, puedo equivocarme. ${ }^{23}$ ¿Cuántas veces no hemos dicho: - ¡ah! Creí saberlo?- ${ }^{24}$ Para saber algo es necesario, apoyar objetivamente lo que afirmo saber, es decir demostrar la imposibilidad de error. ${ }^{25}$ Si esto es así, ¿cómo, entonces, podríamos proceder a demostrar objetivamente nuestra certeza?

¿Intentando ofrecer buenas razones que la apoyen? ¿Cuáles podrían ser unas muy buenas razones para apoyar mi certeza? Parece que ninguna: ni buenas, ni muy buenas, porque todas las razones que pueda aducir para apoyar mi certeza serían más débiles que mi propia certeza. Y todos están de acuerdo en que para apoyar correctamente una afirmación, una hipótesis o una conclusión, deben darse razones que sean más fuertes que estas, porque si no, desde un punto de vista lógico, simplemente no la apoyan.

Bueno, quizás haya alguna regla que nos garantice la imposibilidad de cometer un error. Sin embargo, Wittgenstein dice que no existe tal regla. Porque nos podríamos equivocar al aplicarla y no hay regla alguna que nos indique qué es un error en la utilización de una regla, ${ }^{26} \mathrm{~W}$ ittgenstein concluye "Solo la práctica muestra qué es un error en la utilización de una regla". ${ }^{27}$

\section{III (a) La imagen del mundo no es la razón de las certezas}

¿Podré entonces demostrar que "sé" a partir de la imagen del mundo que he adquirido participando en las prácticas y los juegos del lenguaje con mis semejantes? Wittgenstein contesta que no, y lo hace en base a la siguiente serie argumental:

23 Véase también, Wittgenstein, 1991, §25.

24 Véase Wittgenstein, 1991, §12.

25 Véase Wittgenstein, 1991, §14, 16, 194.

26 En este sentido, véase, Wittgenstein, 1991, §26, 28.

27 Véase Wittgenstein, 1991, §29, 139, 140, 229. 
Lo que ha de ser considerado como prueba suficiente de un enunciado pertenece a la lógica. Pertenece a la descripción del juego de lenguaje (Wittgenstein, 1991, §82).

Sin embargo, "la verdad de algunas proposiciones empíricas pertenecen a nuestro sistema de referencia", ${ }^{28}$ justamente aquellas que todos tenemos, pero sin poder decir cómo es que las adquirimos. ${ }^{29}$ Los enunciados de los que todos estamos ciertos en determinado momento son todos de este tipo, y en ese momento es muy difícil que podamos imaginar algún contexto en el cual pudiéramos negarlos. ${ }^{30}$ Por ejemplo, pregunta Wittgenstein a sus contemporáneos antes del primer viaje espacial: ¿pueden ustedes imaginar algún juego del lenguaje en el cual, ciencia ficción aparte, pudiera negar mi convicción de que nunca me he alejado mucho de la superficie terrestre? ${ }^{? 1}$

¿Qué podría inducirme a creer lo contrario? $\mathrm{O}$ un recuerdo o que me lo hayan dicho. Todo lo que he visto u oído me confirma que nunca persona alguna se ha alejado mucho de la Tierra. En mi imagen del mundo, nada habla a favor de lo contrario (Wittgenstein, 1991, §93) ${ }^{32}$

Pero si bien he obtenido mi imagen del mundo a través de mi interacción en el marco de ciertas prácticas llevadas a cabo por mi comunidad, esto no implica que aquella pueda servir de apoyo a mi proposición, es decir, no significa que mi imagen del mundo pueda calificar como razón para apoyar mi afirmación. Recordemos que comienzo a aprender el juego del lenguaje desde mi más tierna edad, pero no memorizando sus reglas, sino que más bien, aprendo a jugar jugando con mis semejantes. Subrayando, esto significa que:

No tengo mi imagen del mundo porque me haya convencido a mí mismo de que sea la correcta; ni tampoco porque esté convencido de su corrección. Por el contrario, se trata del trasfondo que me viene dado y sobre el que distingo entre lo verdadero y lo falso (Wittgenstein, 1991, §94).

28 Véase Wittgenstein, 1991, §83.

29 Véase Wittgenstein, 1991, §84, 85, 86, 87.

30 Véase Wittgenstein, 1991, \$93.

31 Véase Moore, 1925, p.34.

32 El subrayado es mío. 
Las proposiciones que describen esta imagen del mundo podrían pertenecer a una suerte de mitología... (Wittgenstein, 1991, §95)

A partir de estos dos aforismos, Wittgenstein nos brinda con lo que llamaré su "metáfora del río", la cual describe a lo largo de una serie de aforismos uno a continuación de otro, con la que nos muestra que las imágenes del mundo no son fijas, sino que cambian a lo largo de la historia de la humanidad comenzando su trasformación, justamente, cuando ciertas proposiciones empíricas logran una solidez tal que pasan a ser certezas para todos; y algunas viejas certezas se licuan, por así decirlo, perdiendo su antigua solidez y pasando, a modo de proposiciones empíricas explícitas al torrente de la polémica, para quedar en entredicho o para obtener sus credenciales como conocimiento objetivamente probado o sólidamente argumentado, o bien para morir definitivamente como falsedades. Sin embargo, Wittgenstein considera que a lo largo de la historia la lógica se mantiene firme, como testigo inmutable de aquel continuo movimiento. ${ }^{33}$

Con esta metáfora, Wittgenstein nos dice que podemos imaginar que las certezas son como el lecho firme de un río cuya inmovilidad contrasta con el torrente del agua, misma que fluye al igual que el conocimiento, los pensamientos, las dudas, las hipótesis, las creencias, entre otras, y que, finalmente, la lógica sería como la roca al margen del río, roca que no está sometida a ninguna alteración. Este río, con su roca, su lecho y su caudal, sería como la historia de las imágenes del mundo, suscitadas por distintas formas de vida, a través de la cual va surgiendo poco a poco, o abruptamente, una nueva imagen del mundo para oponerse, transformar o finalmente dar muerte a otra.

No aprendo explícitamente mis certezas. "Puedo descubrirlas posteriormente como el eje en torno al cual gira un cuerpo" (Wittgenstein, 1991, $\S 152)$. La inmovilidad del eje está determinada por el movimiento en torno a él, movimiento del cual participa lo que llamamos "conocimiento".

Por ello considero que Wittgenstein dice que lo que llamamos "conocimiento" puede remover las certezas, obligar a que partes del eje se desprendan y las viejas certezas pasen a participar en el caudal del río que contiene a las creencias y las afirmaciones, de las cuales debemos dar buenas razones para convencer a nuestro interlocutor de que tenemos bases para afirmar lo que afirmamos. ${ }^{34}$

33 Véase Wittgenstein, 1991, § 96-99.

34 Véase, Wittgenstein, 1991, §111. 
Por ejemplo, en varias ocasiones Wittgenstein alude a lo que en su tiempo era una certeza: "yo no he estado nunca en la luna ..." (Wittgenstein, 1991, § 111). En 1950, si Wittgenstein lo sabía, todos sus contemporáneos lo sabían. Sin embargo, en ese mismo año, en ciertos centros de investigación científica, tal certeza era preparada para su demolición en el crisol del conocimiento científico, y muy pronto pasaría la prueba de que estas investigaciones eran adecuadas, mediante su correspondiente avance tecnológico. Pero su transformación del estado "sólido" al estado "líquido", no se llevó a cabo negando dicha certeza: "he estado en la luna", ni dudando de ella entre 1951 y 1968: "dudo si he estado en la luna”. Ningún científico en ese periodo hubiera afirmado tales cosas por mucho que hubiese estado trabajando en el proyecto que llevaría al hombre a la luna; la hipótesis de esta posibilidad no podía ser formulada de aquella manera. Incluso en este contexto esa certeza continuaba manteniéndose. Desde mi punto de vista, la certeza "nunca he estado en la luna" continuó siendo tal hasta el momento mismo en que, dieciocho años después, el 29 de julio de 1969, el primer hombre, Neil Armstrong, puso su pie por primera vez en la luna "licuando" parte del eje. En ese preciso momento tal certeza dejó de serlo porque ya no era compartida por todos. Ya alguien podía decir "sé que he estado en la luna” y contestar a la pregunta “iy cómo lo sabes?", con razones. Además, este hecho desataría una serie de teorías, por ejemplo, acerca de cómo y para qué navegar en el espacio sideral, de experimentos acerca de la composición de las muestras que trajeron los astronautas de la Luna a la Tierra, convirtiéndose en parte del caudal de conocimientos que se van adquiriendo por los científicos. En nuestra cultura contemporánea, a partir de 1969, en principio todos podemos decir que sabemos que el hombre ha estado en la luna y dar razones para apoyar nuestra afirmación.

Una razón fundamental que le permite a Moore suponer que nunca ha estado en la Luna es la de que nadie ha estado nunca en la Luna y nadie podría llegar a ella; y creemos tal cosa sobre la base de lo que aprendemos (Wittgenstein, 1991, §171).35

35 Subrayado en el original. 


\section{III (b) La experiencia no es la razón de las certezas}

En efecto, nadie ha abierto mi cráneo para ver si dentro de él hay un cerebro, pero estamos seguros de que, si lo hiciera, encontraría uno. ${ }^{36}$ "Si un ciego me preguntara: “TTienes dos manos?, no me aseguraría de ello mirándomelas detenidamente. Dado que no sé por qué debería creer a mis ojos si dudara de tal cosa..." (Wittgenstein, 1991, §125). Yo tengo la certeza de que tengo un corazón sin haberme sometido nunca a radiografía alguna, o de que tengo diez dedos en mis pies sin quitarme los zapatos para comprobarlo; no me aseguro de ello mirándolos. "En circunstancias ordinarias no me convenzo de que tengo dos manos mirándomelas. ¿Por qué no? ¿Ha demostrado la experiencia que no es necesario?..." (Wittgenstein, 1991, §133). "Desde que era niño he aprendido a juzgar así: Eso es juzgar." (Wittgenstein, 1991, §128).

¡Cómo!, se podría objetar: "Pero no es la experiencia la que nos enseña a juzgar ası̂”?, es decir, quien nos enseña que es correcto juzgar así?”. Wittgenstein contesta:

¿Cómo nos lo enseña? Nosotros podemos derivarlo de la experiencia, pero la experiencia no nos sugiere cómo derivar algo de ella. Si la experiencia es la razón de que juzguemos de ese modo (y no únicamente la causa), ya no nos queda ninguna otra razón para considerar que eso es una razón (Wittgenstein, 1991, §130).

Que tengo dos manos es, en circunstancias normales, algo tan seguro como cualquier cosa que pudiera aducirse como evidencia al respecto.

Esa es la razón por la que no puedo considerar el hecho de que veo dos manos como una evidencia de ello (Wittgenstein, 1991, §250).

No, la experiencia no es la razón de nuestro juego de hacer juicios. Ni es tampoco su resultado más notable (Wittgenstein, 1991, §131).

\section{III (c) Las reglas no son la razón de las certezas}

Aprendemos los juegos del lenguaje jugando con nuestros semejantes, y es así como vamos adquiriendo aquello de lo que estamos ciertos, aquello que

36 Véase Wittgenstein, 1991, §118. 
no podemos poner en duda. Desde este punto de vista, es en nuestras prácticas donde comúnmente se muestra que tenemos esas certezas, pero no hay algunas certezas que no puedan ser demolidas por esas prácticas. Hoy tenemos la firme convicción, la certeza, de que la Tierra es un esferoide y no es plana; no lo ponemos en duda; sin embargo, en alguna época los hombres estaban convencidos de que la Tierra era plana. Para decirlo de manera más filosófica: ¿Estamos convencidos o sabemos que no debemos cometer la falacia naturalista?. Muchos filósofos incurren en ella conscientemente sin remordimiento alguno. O simplemente, sabemos que es nocivo fumar y dicen que incluso inhalar el humo del cigarro de otro, por ende está prohibido para todos fumar en lugares cerrados; sin embargo, hay mucha gente que a sabiendas contraviene la regla. Wittgenstein dice:

Es evidente que nuestras afirmaciones empíricas no son todas del mismo tipo, dado que es posible aislar una proposición [...] y transformarla, de proposición empírica, en norma de descripción. (Wittgenstein, 1991, §167)

No son los axiomas aislados los que nos parecen evidentes, sino todo un sistema cuyas consecuencias y premisas se sostienen recíprocamente (Wittgenstein, 1991, §142).

Las reglas no son suficientes para normar una práctica [...] Nuestras reglas dejan alternativas abiertas y la práctica debe hablar por sí misma (Wittgenstein, 1991, §139).

En efecto, es posible que muchas de nuestras certezas, como aquella de que "una sustancia A siempre reacciona del mismo modo ante una sustancia B dadas las mismas circunstancias" (Wittgenstein, 1991, §168), hayan pasado de ser proposiciones empíricas en controversia a ser normas de descripción. ${ }^{37}$

...Pero también es posible que desde tiempos inmemoriales [algunas] pertenezcan al andamiaje de todas nuestras consideraciones... (Wittgenstein, 1991, §211)

No puedo decir que tenga buenas razones en favor de la opinión de que los gatos no nacen de los árboles o de que he tenido un padre y una madre (Wittgenstein, 1991, §282)

37 Véase Wittgenstein, 1991, §167, 168, 211. 
La ardilla no llega por medio de la inducción a la conclusión de que el próximo invierno también va a necesitar reservas. Tampoco nosotros necesitamos un principio inductivo para justificar nuestras acciones y nuestras predicciones (Wittgenstein, 1991, §287).

\section{III (d) La evidencia empírica no es la razón de las certezas}

Hemos visto que para Wittgenstein, mi imagen del mundo es "el sustrato de todas mis investigaciones y afirmaciones", pero "las proposiciones que la describen no están todas sometidas del mismo modo a la comprobación” (Wittgenstein, 1991, §162). Hay algunas que no comprobamos, pero "cuando comprobamos una cosa, ya lo hacemos presuponiendo que algo no se comprueba” (Wittgenstein, 1991, §163). Pero ello no significa que esto que no comprobamos sea parte de las premisas, ni que sea verdadero o falso.

Recordemos que la consideración: "una sustancia A siempre reacciona del mismo modo ante una sustancia B dadas las mismas circunstancias" es una certeza de nuestro tiempo, de nuestra imagen del mundo, que yace en el fondo de todo experimento químico o culinario, pero no como parte de una hipótesis determinada ni como premisa de su demostración.

Creo que los hombres se comunican de cierto modo. Así es como creo en hechos geográficos, químicos, históricos, etc. Es así como aprendo las disciplinas científicas. En efecto aprender se basa en la creencia. Quien ha aprendido así [...] dice que lo sabe... (Wittgenstein, 1991, §170).

Lo sé, digo, le digo a otro; y aquí hay una justificación. Pero no la hay para mi creencia (Wittgenstein, 1991, §175).

Hago afirmaciones sobre la realidad con distintos grados de seguridad. ¿Cómo se manifiesta el grado de seguridad? ¿Qué consecuencias tiene?... (Wittgenstein, 1991, §66)

Podría suponer que Napoleón nunca hubiera existido y que no fuera más que una fábula, pero no que la Tierra no existía hace ciento cincuenta años (Wittgenstein, 1991, §186).

El punto de estos aforismos es que el que Napoleón haya perdido la batalla de Waterloo, aunque pudiera parecer una certeza, no lo es, ya que las consecuencias de dudar de ello me obligarían a explicar los hechos históricos 
de una manera diferente, pero esto no alteraría totalmente al resto de la evidencia histórica. Ahora bien, el que la Tierra existe hace más de ciento cincuenta años sí es una de nuestras certezas, porque dudar de ella atenta contra toda la evidencia en la que se apoya la diversidad de las ciencias con las que contamos, así como de todas las diferentes culturas habidas a través de de la historia; dudar de esta certeza haría de toda la evidencia acumulada hasta ahora, una ficción. Wittgenstein lo pone del siguiente modo:

Me parece que quien dude de la existencia de la Tierra en aquel tiempo (hace 150 años) atenta contra la esencia de toda la evidencia histórica. Pero no puedo decir que ésta sea definitivamente correcta." (Wittgenstein, 1991, §188). En uno u otro momento se ha de pasar de la explicación a la mera descripción (Wittgenstein, 1991, §189).

Si ahora todo habla en favor de una hipótesis, y no hay nada que hable en contra - ¿Es verdadera con toda certeza? Podemos expresarlo así. -Pero, ¿está de acuerdo tal hipótesis con la realidad, con los hechos? (Wittgenstein, 1991, §191).

Estos aforismos apuntan al hecho de que las hipótesis científicas que están basadas en un amplio y excelente conjunto de evidencia empírica, no por ello son necesariamente verdaderas. Wittgenstein dice que la siguiente oración:

"La proposición es verdadera o falsa" sólo quiere decir que ha de ser posible decidir a favor o en contra de ella. Pero con ello no se proporciona el tipo de fundamento que corresponde a tal decisión (Wittgenstein, 1991, §200). ...la fundamentación la justificación de la evidencia tiene un límite; -pero el límite no está en que ciertas proposiciones nos parezcan verdaderas de forma inmediata, como si fueran una especie de ver por nuestra parte; por el contrario, es nuestra actuación la que yace en el fondo del juego del lenguaje (Wittgenstein, 1991, §204).

En efecto, del hecho de que toda la evidencia hable a favor de una hipótesis, no se sigue que esta esté "de acuerdo sin restricciones con el mundo de los hechos”. Wittgenstein considera que el que digamos que sí lo está, solo muestra el significado de las palabras "estar de acuerdo". De aquí que podamos concluir que tampoco la evidencia puede ser la razón de nuestras certezas. 


\section{Las certezas se adquieren en y por las prácticas y constituyen el fun- damento de todo conocimiento}

Ahora trataré de mostrar la conexión que establece Wittgenstein entre las certezas y el conocimiento, las cuáles, para él, corresponden a categorías diferentes. Considero que la clave se encuentra en su siguiente aforismo:

En el fundamento de la creencia bien fundamentada, se encuentra la creencia sin fundamentos (Wittgenstein, 1991, §253).

Fortalecer esta última cita requiere de apoyo extra. Para esto, regresemos al punto acerca de la verdad. Preguntemos, ¿qué quiere decir para Wittgenstein que una proposición sea verdadera? Es decir: "¿cuándo es objetivamente cierta?". Él contesta: "cuando el error no es posible” (Wittgenstein, 1991, §194).

Ahora bien, según nuestro autor, las palabras adquieren su significado a través de los juegos del lenguaje constituidos a través de las prácticas de una determinada comunidad de hablantes. En efecto, él considera que jugándolos con nuestros semejantes aprendemos el significado de las palabras; además, considera que la fundamentación o la justificación de nuestras creencias tienen un límite, puesto que somos personas finitas. Pero, ¿cuál es este límite? El límite es nuestra actuación en el marco de nuestras prácticas ligüísticas: ${ }^{38}$

Si lo verdadero es lo que tiene fundamentos, el fundamento no es verdadero, ni tampoco falso (Wittgenstein, 1991, §205).

Y es que nuestras prácticas no son ni verdaderas ni falsas. Wittgenstein dice que "Nuestro hablar obtiene su sentido del resto de nuestra actuación" (Wittgenstein, 1991, §229). Pero si con la expresión "sé que tal y tal” queremos decir que sabemos, tenemos que demostrarlo objetivamente. "Y es así como se ha de decidir si algo es o no conocimiento" (Wittgenstein, 1991, §230).

Si de lo que se trata es de saber, y no sólo de nuestras convicciones; es decir, si de lo que se trata es de una demostración objetiva, entonces:

38 Véase Wittgenstein, 1991, § 204, 229, 298, 427, 428, 431, 440 y 446. 
Se dice "Sé ..." cuando se está en condiciones de dar razones apropiadas. "Sé ..." está vinculado a la posibilidad de demostrar la verdad. Si alguien sabe algo -siempre que esté convencido-se puede poner esto de manifiesto. Pero si lo que cree es de tal tipo que las razones que puede dar no son más seguras que su aserción, no puede decir que sabe lo que cree (Wittgenstein, 1991, \$243). ${ }^{39}$

Quien puede poner en duda una certeza, rechaza toda nuestra imagen del mundo y todo nuestro sistema de verificación (Wittgenstein, 1991, §279). Los hombres aprenden de sus experiencias, pero en sus acciones muestran que creen firmemente en ciertas cosas, tanto si expresan tales creencias como si no lo hacen... (Wittgenstein, 1991, §284). ${ }^{40}$

De aquí que nuestro autor considere que un sistema de certezas se adquiere en y por nuestras prácticas, nuestros juegos del lenguaje, y que ello constituye el fundamento de todo conocimiento. Para Wittgenstein, las certezas de una comunidad constituyen un sistema:

...Mis convicciones constituyen un sistema (Wittgenstein, 1991, §103).

Cualquier prueba, cualquier confirmación y refutación de una hipótesis, ya tiene lugar en el seno de un sistema. Y tal sistema no es un punto de partida más o menos arbitrario y dudoso de nuestros argumentos, sino que pertenece a la esencia de lo que denominamos argumentación. El sistema no es el punto de partida, sino el elemento vital de los argumentos (Wittgenstein, 1991, §105).

\section{Conclusiones}

En suma, no pueden contar como razón de las certezas:

1. Ni las imágenes del mundo, porque estas cambian históricamente y no son ni verdaderas ni falsas;

2. Ni la experiencia, porque esta no nos enseña cómo hacer juicios ni cómo dar razones.

3. Ni las reglas, pues estas no son suficientes para fijar las prácticas mediante las cuales se adquieren las certezas de una comunidad de hablantes.

39 El subrayado es mío.

40 El subrayado es mío. 
4. Ni la evidencia empírica, porque no puedo asegurar que esté efectivamente de acuerdo "con el mundo de los hechos", ni que la toda la evidencia acumulada en los libros de ciencia contemporáneos sea en efecto verdadera.

5. Conclusión 1: por lo tanto, no hay argumento alguno capaz de ofrecer razones más seguras que nuestras certezas.

6. Conclusión 2: por lo tanto; las certezas no son conocimiento.

Considero que el viaje a través de la exégesis de esta serie argumental, así como las conclusiones (1) y (2), apoyan las ideas de Gallardo de las que hablé en mi introducción, según las cuales el segundo Wittgenstein, argumentó exitosamente, que el lenguaje humano adquiere sus significados mediante el "modo en que se utilizan las palabras en diversos contextos", que "estos contextos dependen, a su vez, de las 'formas de vida' de una comunidad." y que los aportes del filósofo austriaco también alumbran problemas fundamentales "que atañen [específicamente] al estatus y la naturaleza del conocimiento".

En efecto, hemos visto por otro camino y con otro razonamiento que guarda un "parecido de familia" con las dos afirmaciones de Gallardo, que Wittgenstein presenta un movimiento argumental, difícil de evadir, que consiste en sostener que el sistema de certezas corporizadas en las prácticas contextuales de una comunidad de hablantes, no puede calificar como conocimiento porque no se puede justificar epistémicamente.

Espero haber mostrado, a partir de mi exégesis, que la sucesión de la diversidad de formas de vida humanas, con todo lo que ellas implican, consiste en recorrer una espiral siempre abierta al devenir histórico, es decir, que el sistema de certezas corporizadas, se adquiere casi imperceptiblemente en y por las prácticas contextuales cuyas "reglas dejan alternativas abiertas" a estas y, por ende, las prácticas deben hablar por sí mismas (como lo dice Wittgenstein en singular). Así, el sistema de certezas va cambiando poco a poco a la zaga del sistema de conocimientos que se va adquiriendo, así, aquel funciona dependiendo del contexto correspondiente, como los hilos invisibles de acuerdos que permiten justificar, no solo a muchas creencias de sentido común que no son certezas, sino incluso a los diversos puntos de vista, posiciones y afirmaciones de legos y filósofos, científicos y experimentalistas (controversiales o no) que los hablantes sostenemos en el marco de nuestras respectivas comunidades. 


\section{Referencias}

Ariso, J. M. (2008). Acerca del supuesto fundamentalismo de Wittgenstein en Sobre la certeza. Contrastes. Revista Internacional de Filosofía. v. XIII, 273-284

Ariso, J. M. (2012). ¿Tiene sentido hablar de un "tercer Wittgenstein" posterior a 1946 ? Logos. Anales del Seminario de Metafísica 45, 223-242.

Fernandois, E. (2013). Ni fundacionismo ni coherentismo. Una lectura antropológica de Sobre la Certeza. Revista de Filosofía 69, 99-117. http://dx.doi.org/10.4067/ S0718-43602013000100009

Gallardo, A. (2011). Wittgenstein: epistemología y lenguaje. PRAXIS 66, 87-97.

Moore, G. E. (1925). A Defense of Common Sense. In Philosophical Papers. New York: Collier Books.

Moore, G. E. (1936). Proof of an External World. In Philosophical Papers. New York: Collier Books.

Moyal-Sharrock, D. (ed.) (2004). The Third Wittgenstein. UK: Ashgate.

Moyal-Sharrock, D. \& W. H. Brenner (eds.) (2007). Readings of Wittgenstein's On Certainty. UK/USA: Palgrave Macmillan.

Pinto, S. (2004). Dos estrategias de ataque al Mito de lo Dado: Wittgenstein y Sellars. Episteme v. 24, n. 1, 53-73.

Santibáñez, C. (2011). Certeza animal: ¿Un tercer Wittgenstein? Atenea 504, 117-190.

Santibáñez, C. (2012). Esa cierta animalidad. ¿Se cerró un círculo entre Russell y Wittgenstein? Teorema v. XXI, n. 1, 27-46.

Villoro, L. (1987). Creer, saber, conocer. México: s XxI.

Wittgenstein, L. (2003). Investigaciones filosóficas. México: Universidad Nacional Autónoma de México.

Wittgenstein, L. (1991). Sobre la certeza. (Traducción de J. L. Prades y V. Raga). Barcelona: Gedisa. 